Tarbawy : Jurnal Pendidikan Islam

ISSN : 2407-4462 (Cetak), 2614-5812 (Elektronik)

Vol. 6, No. 2, 2019, Hal. 86 - 92

DOI: https://doi.org/10.32923/tarbawy.v6i2.1238

\title{
Implementasi E-learning Sebagai Media Pembelajaran Pada Era Milenial
}

\author{
Dian Puspita Eka Putri ${ }^{1}$ \\ ${ }^{1}$ IAIN Syaikh Abdurrahman Siddik Bangka Belitung
}

\begin{tabular}{l}
\hline \hline Info Artikel : \\
\hline Diterima 12 Agustus, 2019 \\
Direvisi 13 Oktpber 2019 \\
Dipublikasikan 1 Desember 2019
\end{tabular}

\section{Kata Kunci:}

E-learning

Media Pembelajaran

Era Milenial
Keywords:

E-learning

Intructional Media

Milennial Era

\begin{abstract}
ABSTRAK
Penelitian ini bertujuan untuk mendekripsikan bagaimana cara mengiplementasikan prosen kegiatan belajar mengajar yang berbasis E-learning pada era dan generasi milenial. Kemudian untuk mengetahui bagaimana pembelajaran berbasis E-learning dapat membangun minat belajar siswa. Penelitian ini merupakan penelitian deskripif dengan pendekatan kuanlitatif. Populasi penelitian ini adalah mahasiswa Program Sarjana Pendidikan Agama Islam kelas A-C tahun 2018. Penentuan sampel menggunakan teknik sampling jenuh dengan jumlah 57 mahasiswa. Pengumpulan data menggunakan teknik wawancara, observasi dan dokumentasi. Hasil dari penelitian ini adalah cara megimplementasikan E-learning sebagai media pembelajaran dilakukan dengan melalui tiga tahap yaitu perencanaan, penggunan dan evaluasi. Hasil lain juga didapat bahwa dengan menggunaka E-learning dapat membangun minat belajar. Hal ini dikarena pembelajaran berbasis E-learning dapat menyajikan materi dan memberikan pengalaman belajar yang bervariasi.
\end{abstract}

\begin{abstract}
This study aims to describe how the implementation of the process teaching and learning activities based on E-learning in the era and millennial generation. Then to find out how E-learning based learning can build student learning interest. This research is a descriptive study with a quantitative approach. The population of this research is the students of the A-C Class Islamic Education Bachelor Program in 2018. The determination of the sample uses a saturated sampling technique with a total of 57 students. Data collection using interview, observation and documentation techniques. The results of this study are how to implement E-learning as a learning medium carried out through three stages, namely planning, use and evaluation. Other results are also obtained that by using E-learning can build interest in learning. This is because Elearning based learning can present material and provide a varied learning experience.
\end{abstract}

This is an open access article distributed under the Creative Commons Attribution License, which permits unrestricted use, distribution, and reproduction in any medium, provided the original work is properly cited. (C2019 by author.

\section{Koresponden:}

Dian Puspita Eka Putri

Email: dianpuspitaekap@iainsasbabel.ac.id

\section{Pendahuluan}

Kegiatan belajar mengajar sering diistilahkan dengan proses pembelajaran (Putri, 2019). Proses pembelajaran Sebagian besar dilakukan di lingkungan sekolah (Simanihuruk et al., 2019). Pembelajaran selama ini selalu menempatkan siswa sebagai obyek yang harus diisi oleh sejumlah ragam informasi dan sejumlah bahan-bahan ajar setumpuk lainnya (Maghfiroh, 2019). Terjadi komunikasi hanya satu arah yaitu antara guru ke siswa (Danim, 2008). Banyak proses pembelajaran dilakukan oleh guru menggunakan pendekatan ekspositori (Setiawan, Nurlaela, \& Yundra, 2019). Pendekatan ini menjadi andalan guru dalam memilih metode pembelajaran. Kegaiatan atau Interaksi semacam berdampak pada pembelajaran verbalisme yang semakin meningkat. Sehingga interaksi seperti ini disebut juga pembelajaran konvensional.(Setiawan et al., 2019) 
Salah satu masalah Pendidikan yang dialami oleh bangsa Indonesia adalah rendahnya kualitas Pendidikan itu sendiri (Miarso, 2009). Baik itu input, proses, autpun ataupun outcome Pendidikan. Hal ini dapat dilihat dari laporan Bank Dunia tentang mutu pendidikan Indonesia yang sangat memprihatinkan (Soejanto, 1995). Sedangkan dari segi proses pendidikan khususnya pembelajaran sebagian besar guru lebih cenderung bertumpu pada aspek kognitif tingkat rendah seperti mengingat, menghafal, dan menumpuk informasi (Basri, 2014). Jika Dikaitkan dengan tuntutan masa depan, Pendidikan bukan hanya bersifat penyampaian informasi yang kompetetif, tapi juga berkaitan dengan berbagai kemajuan teknologi dan informasi (Praherdhiono et al., 2019)

Perkembangan teknologi informasi telah memasuki berbagai sendi kehidupan, termasuk dunia pendidikan lebih khususnya pembelajaran (Ningrum \& Rosita, 2019). Pendidikan dan pembelajran telah diintervensi oleh keberadaan teknologi (Yeni \& Fitri, 2019). Seiring dengan perkembangan aplikasi teknologi informasi dalam dunia pendidikan, maka berbagai bahan belajar pun telah diproduksi dan dikonsumsi oleh pembelajar melalui medium teknologi dalam bentuk kemasan yang sangat bervariasi seperti: facebook, twitter, blog, website, dan sebagainya (Wardani, Sishadiyati, \& Fitriyah, 2019). Dimana hal ini sangat berbeda dengan proses pembelajaran tradisional (konvesional) yang mengandalkan guru sebagai sumber belajar yang pertama dan utama sedangkan sumber yang lain hanyalah pelengkap. Pembelajaran generasi milenial sudah bergeser pada pembelajaran yang menerapkan teknologi dalam prosesnya (Handoko, 2019)

Generasi milenial (millennial generation) itu sendiri adalah generasi yang lahir dalam rentang waktu awal tahun 1980 hingga tahun 2000 atau Gen-Y (Yeni \& Fitri, 2019). Disebut generasi milenial karena generasi yang hidup di pergantian millennium bersamaan dengan masuknya teknologi digital ke segala sendi kehidupan (Praherdhiono et al., 2019). Teknologi digital yang telah menjadi kebutuhan dasar pada generasi ini. Pada generasi milenial, yaitu generasi yang sudah melek teknologi digital, dimana tiap informasi dengan mudah diakses lewat internet. Oleh karena itu khalayak umum lebih mengenal dengan sebutan era milenial (Handoko, 2019)

Jika pengintegrasian pola belajar yang menggunakan teknologi informasi dan keleluasaan generasi milenial dalam menggali informasi dibuat, maka kualitas sistem pembelajaran ini diharapkan mampu secara cepat memperbaiki berbagai kelemahan pendidikan yang ada (Simanihuruk et al., 2019). Salah satu cara yang dapat dikembangkan adalah mengubah sistem pembelajaran konvensional dengan sistem pembelajaran yang lebih efektif dan efisien dengan dukungan sarana dan prasarana yang memadai (Bariyah, 2019). Pembelajaran dengan memanfaatkan sarana teknologi informasi jaringan internet merupakan salah satu alternatif yang tepat dan dapat mengatasi berbagai persoalan pembelajaran (Andayani \& Larasati, 2019). Sistem pendidikan di Indonesia keberadaannya sangat heterogen karena terbentur masalah letak geografis yang sangat besar pengaruhnya terhadap kemajuan teknologi informasi (Sastrawijaya, 1991)

Pemanfaatan teknologi informasi dalam pembelajaran menyebabkan sistem penyampaian materi pelajaran dapat dilakukan tanpa harus tatap muka antara guru dengan siswa, akan tetapi bentuk belajar yang terpisah antara guru dengan siswa juga dapat dilakukan (Ningrum \& Rosita, 2019). Penerapan teknologi ini dalam pendidkan terlihat dari pemgunaan jaringan komputer, internet, laboratorium, dan lain-lain (Praherdhiono et al., 2019). Pembelajaran dengan memanfaatkan teknologi ini sering disebut juga dengan Elektronic Leraning (E-learning) (Andayani \& Larasati, 2019)

Menurut (Setiawan et al., 2019)Pengertian E-learning sendiri ditinjau dari epistemologisnya tersusun dari dua bagian, yaitu 'e' yang merupakan singkatan dari 'electronica' dan 'learning' yang berarti 'pembelajaran'. Jadi E-learning berarti pembelajaran dengan menggunakan jasa bantuan perangkat elektronika. Jadi dalam pelaksanaannya, E-learning menggunakan jasa audio, video atau perangkat komputer atau kombinasi dari ketiganya. Dengan kata lain E-learning adalah pembelajaran yang dalam pelaksanaannya didukung oleh jasa teknologi seperti telepon, audio, videotape, transmisi satelite atau komputer (Wardani et al., 2019)Sejalan dengan itu, Onno W. Purbo dalam (Praherdhiono et al., 2019) menjelaskan bahwa istilah "e" dalam E-learning adalah segala teknologi yang digunakan untuk mendukung usaha- usaha pengajaran lewat teknologi elektronik internet.

Secara lebih singkat (Hutagalung, Winata, \& Jaya, 2019) mengemukakan bahwa E-learning merupakan kegiatan pembelajaran berbasis web (yang bisa diakses dari internet). Tidak jauh berbeda dengan itu (Bariyah, 2019) secara sederhana mengatakan bahwa E-learning merupakan kegiatan pembelajaran yang memanfaatkan jaringan internet sebagai metode penyampaian, interaksi, dan fasilitas yang didukung oleh berbagai bentuk layanan belajar lainnya. Sebenarnya materi E-learning tidak harus di distribusikan secara online baik melalui jaringan lokal maupun intemet. Interaksi dengan tanpa menggunakan internetpun bisa dijalankan secara online dan real-time ataupun secara off-line atau archieved (Danim, 2008). Distribusi secara offline menggunakan media CD/DVD pun termasuk pola E-learning 
(Setiawan et al., 2019). Dalam hal ini aplikasi dan materi belajar di kembangkan sesuai kebutuhan dan di distribusikan melalui media CD/DVD, selanjutnya pembelajar dapat memanfatkan CD/DVD tersebut dan belajar di tempat dimana siswa berada (Putri, 2019).

\section{Metode}

Penelitian ini merupakan penelitian deskriptif dengan pendekatan kuanlitatif. Subjek penelitian adalah seluruh mahasiswa Program Studi Pandidikan Agama Islam kelas A-C angakatan 2018 Fakultas Tarbiyah IAIN Syaikh Abdurrahman Siddik Bangka Belitung yang berjumlah 57 orang. Teknik sampling yang digunakan adalah teknik sampel jenuh sehingga memungkinkan semua subjek terpilih menjadi sampel. Penelitian dilakukan pada bulan Juli 2020. Pengumpulan data dilakukan menggunakan teknik obsevasi, wawancara dan dokumentasi. Butir soal wawancara dikonstruk berdasarkan tiga indikator dan variable penelitian yaitu implentasi E-learning, media pembelajran online dan penggunaanya pada gerenasi atau era milenial. Validitas instrumen berupa validitas isi (content validity) yang dibuktikan melalui penilaian pakar (expert judgement). Pakar berjumlah 2 orang pakar dibidang Teknologi Pembelajaran. Hasil penelitian ini diolah dan disajikan dalam bentuk deskripsi implentasi pembelajaran online pada era milenial.

\section{Hasil dan Pembahasan}

Electronic Learning (E-learning) pada hakikatnya adalah belajar atau pembelajaran melalui pemanfaatan teknologi komputer atau internet (Bariyah, 2019). Teknologi pembelajaran seperti itu juga dapat disebut pembelajaran berbasis web (Web Based Instuction) (Susilo \& Rohman, 2019). Pembelajaran Elearning bukan hanya pembelajaran yang memperkenalkan teknologi semata kepada siswa, tetapi juga membantu guru untuk mengintegrasikan teknologi selama proses pembelajaran (Hutagalung et al., 2019). E-learning juga termasuk media Pembelajaran, yang dapat diambilakasikan dalam penyampaian materi (Putri \& Muhtadi, 2018). Teknologi pendidikan mengarah kepada prosedur ilmiah berdasarkan metodologi tertentu dalam rangka penyelenggaraan Pendidikan (Miarso, 2009). Ia tidak sama dengan pola-pola tradisional dalam kegiatan pendidikan (Danim, 2008:14). Oleh karena itu, guru harus melakukan terobosan baru dalam pelaksanaan proses pembelajaran, dan sebaliknya guru harus meninggalkan proses pembelajaran konvensional (cara-cara lama) yang selama ini dinilai kurang efektif (Soejanto, 1995).

Beberapa model pembelajaran E-learning yang layak dipertimbangkan sebagai dasar pengembangan sistem pembelajaran dengan mendayagunakan internet, yaitu: (1) Web Course; (2) Web Centric Course; dan (3) Web Enhanced Course,(Simanihuruk et al., 2019). Pertama, Web Course adalah penggunaan internet untuk keperluan pembelajaran, di mana seluruh bagian bahan belajar, diskusi, konsultasi, penugasan, latihan dan ujian sepenuhnya disampaikan melalui internet. Siswadan guru sepenuhnya terpisah, namun hubungan atau komunikasi antara keduanya bisa dilakukan setiap saat. Komunikasi lebih banyak dilakukan secara ansynchronous daripada secara synchronous. Bentuk web course ini tidak memerlukan adanya kegiatan tatap muka baik untuk keperluan pembelajaran maupun evaluasi dan ujian, karena semua proses pembelajaran sepenuhnya dengan menggunakan fasilitas internet seperti: email, chat rooms, bulletin board dan online conference. Selain itu, sistem ini biasanya juga dilengkapi dengan berbagai sumber belajar (digital), baik yang dikembangkan sendiri maupun dengan menggunakan berbagai sumber belajar dengan jalan membuat hubungan (link) ke berbagai sumber belajar yang sudah tersedia pada internet, seperti data base statistic berita yang sudah tersedia pada internet, seperti data base statistic dan informasi, e-book, perpustakaan elektronik dan lain-lain. Bentuk pembelajaran model ini biasanya digunakan keperlukan pendidikan jarak jauh (distance education/learning). Aplikasi bentuk ini antara lain virtual universitas ataupun lembaga pelatihan yang menyelenggarakan pelatihan-pelatihan yang bisa diikuti secara jarak jauh dan setelah lulus ujian diberikan sertifikat. (Susilo \& Rohman, 2019)

Kedua, Web Centric Course, adalah penggunaan internet untuk keperluan pembelajaran, di mana seluruh bagian bahan belajar, diskusi, dan penugasan (Simanihuruk et al., 2019). Sedangkan konsultasi, diskusi dan latihan dilakukan secara tatap muka, walaupun dalam proses belajarnya sebagian dilakukan dengan tatap muka tetap lebih kecil dibandingkan dengan prosentase proses pembelajaran melalui internet. Bentuk ini memberikan makna bahwa kegiatan belajar bergeser kegiatan di kelas menjadi kegiatan melalui internet sama dengan bentuk web course, siswa dan guru sepenuhnya terpisah tetapi pada waktu-waktu yang telah ditetapkan, keduanya bertatap muka baik di sekolah maupun di tempat-tempat yang telah ditentukan seperti di ruang perpustakaan, taman bacaan, ataupun di balai pertemuan. 
Penerapan bentuk ini sebagaimana yang telah dilakukan pada perguruan tinggi terkemuka yang menggunakan sistem belajar secara of campus (Basri, 2014)

Ketiga, Web Enhanced Course adalah pemanfaatan internet untuk pendidikan, untuk menunjang peningkatan kualitas pembelajaran di kelas (Simanihuruk et al., 2019). Bentuk ini juga dikenal dengan nama web lite course (jaringan pembelajaran dengan biaya murah), karena kegiatan pembelajaran utama adalah tatap muka di kelas.Peranan internet di sini adalah untuk menyediakan sumber-sumber belajar yang sangat kaya akan informasi dengan cara memberikan alamat-alamat atau membuat link ke perlabagai sumber belajar yang sesuai dan bisa diakses secara online, untuk meningkatkan kuantitas dan memperluas kesempatan komunikasi antara guru dengan siswasecara timbal balik (feed back). Dialog atau komunikasi dua arah tersebut dimaksudkan untuk keperluan berdiskusi, berkomunikasi, maupun untuk bekerja secara kelompok. Berbeda dengan kedua bentuk sebelumnya (Web Course dan Web Centric Course), bentuk Web Enhanced Course ini prosentase pembelajaran melalui internet berbasis teknologi informasi, sebelum menyelenggarakan pembelajaran dengan internet secara lebih kompleks, seperti web course dan web centric course (Setiawan et al., 2019).

Baik pada model ataupun web course, web centric course, dan web enhanced course, terdapat beberapa komponen aktivitas seperti informasi, bahan belajar, pembelajaran ataupun komunikasi, penilaian yang bervariasi. Secara umum komponen aktivitas dan strukturnya dapat diterapkan dalam pengembangan pembelajaran melalui internet (Andayani \& Larasati, 2019).

\section{Implementasi E-learning Sebagai Media Pembelajaran}

Pembelajaran yang berbasis E.Learning adalah suatu disiplin ilmu terapan (Bariyah, 2019). Maknanya E-learning berkembang akibat adanya kebutuhan. Yaitu kebutuhan untuk membuat proses belajar lebih aktif, efisien, melalui teknologi yang berkembang (Praherdhiono et al., 2019). (Andayani \& Larasati, 2019) menyebutkan bahwa implementasi kegiatan pembelajaran E-learning mencakup tentang perencanaan, implementasi, dan evaluasi.

Menurut (Andayani \& Larasati, 2019) Perencanaan, merupakan gambaran atau deskripsi rencana (skenario) yang menjelaskan mengenai beberapa kegiatan yang akan dilaksanakan pada saat berlangsungnya pembelajaran(Andayani \& Larasati, 2019). Dalam konteks pembelajaran berbasis $E$ learning perencanaan mencakup tentang rencana, gambaran umum aktivitas pembelajaran dengan menggunakan jaringan komputer, perencanaan ini memuat 3 (tiga) komponen yaitu: materi atau bahan ajar, kegiatan selama pembelajaran, dan evaluasi (Hutagalung et al., 2019). Materi atau Bahan ajar berfungsi untuk menyampaikan informasi untuk mencapai tujuan pembelajaran. Penggunaan bahan ajar pada E-learning dapat memanfaatkan buku yang sudah tersedia, juga dapat secara langsung mengakses bahan ajar atau informasi pada halaman web yang sudah dibuat sebelumnya (Wardani et al., 2019). Bahan ajar pada E-learning hanya memuat pokok-pokonya saja, sementara deskripsi lengkap dari pokokpokok bahan ajar disediakan dalam halaman web yang akan diakses siswa Kegiatan pembelajaran yang tercakup pada perencanaan adalah metode pembelajaran, aktivitas dan tindakan pembelajaran serta alat atau media pembelajaran. (Hutagalung et al., 2019)

Implementasi, menurut (Wardani et al., 2019) pada Langkah ini terdapat beberapa model pembelajran dalam penerapan E-learning yang bisa digunakan, yaitu: Selective Model, Sequential Model, Static Station Model, dan Laboratory Model. Selective Model, model ini dapat digunakan jika komputer di sekolah sangat terbatas (satu komputer). Dalam hal ini guru harus memilih alat atau media yang tersedia dan dirasakan tepat untuk menyampaikan bahan pelajaran dengan jaringan yang tersedia. Sehingga sifatnya mendemostrasikan informasi kepada siswa. Sequential Model, model ini digunakan jika komputer di sekolah terbatas (dua atau tiga komputer). Para siswa dalam kelompok secara bergiliran menggunakan komputer untuk mencari sumber pelajaran yang dibutuhkan. siswa menggunakan E-learning sebagai bahan rujukan untuk mencari informasi baru. Static Station Model, model ini jika komputer di sekolah lebih dari satu namun tidak memenuhi kebutuhan siswa tiap indivisu, sebagaimana pada model Sequential Model. Dalam model ini guru memiliki beberapa sumber belajar yang berbeda untuk mencapai tujuan pembelajaran yang sama. Bahan E-learning digunakan oleh satau atau dua kelompok siswa untuk mencapai tujuan pembelajaran yang telah ditetapkan. Laboratory Model, model ini digunakan jika tersedia sejumlah komputer yang dapat dipakai semua siswa di sekolah. laboratorium ini dilengkapi dengan jaringan internet, mana warga sekolah dapat menggunakannya secara leluasa (setiap warga sekolah 
menghadapi satu komputer). Dalam hal ini bahan E-learning dapat digunakan sebagai bahan pembelajaran mandiri (Maghfiroh, 2019)

Evaluasi, (Setiawan et al., 2019) menyatakan bahwa evaluasi berfungsi untuk mengukur ketercapaian tujuan pembelajaran selama proses atau kegiatan pembelajaran. Kemudian menuyusun tindakan apa yang harus dilakukan apabila tujuan belum dicapai. Pada pembelajaran E-learning evaluasi dilakukan dengan cara bervariasi, seperti setiap siswa dapat melihat dan mengikuti instruksi di halaman web. Instruksi dapat berupa pernyataan, tugas-tugas, dan atau latihan-latihan yang harus dikerjakan siswa (Bariyah, 2019)

\section{Implementasi E-learning Dapat Membangun Minat Belajar Siswa Milenial}

Minat adalah salah satu faktor yang menentukan tercapai atau tidaknya usaha siswa dalam belajar (Sastrawijaya, 1991). Perhatian siswa akan besar apabila tugas belajar itu mempunyai nilai pribadi sehingga membuat minat belajar menjadi besar (Singer, 1987). Minat erat hubungannya dengan kebutuhan, minat yang berasal dari kebutuhan akan menjadi faktor pendorong bagi anak dalam melaksanakan usaha belajarnya (Soejanto, 1995). Sehingga minat sangat penting dalam proses pembelajaran Minat dapat dimunculkan dan dipertahankan dengan menyajikan pengalaman yang beragam dan bervariasi (Handoko, 2019). Apabila minat belajar siswa sudah tumbuh, maka dorongan dan motivasi belajar juga kuat sehingga tujuan pembelajaran dapat tercapai (Singer, 1987). Hal ini selaras dengan (Soejanto, 1995)yang menyatakan bahwa minat sangat besar pengaruhnya terhadap keberhasilan belajar, karena belajar harus dengan minat atau perhatian.

Proses kegiatan belajar yang ditawarkan E-learning mampu menyajikan pengalaman yang bervariasi. Mulai dari gaya belajar visual, audio, audio visual dan kinestetik. Sehingga E-learning dapat dijadikan sebagai media pembelajaran yang dapat membangun dan mempertahankan minat belajar siswa. Dengan catatan bahwa guru sebagai fasilitator pembelajaran mampu memilih dan melakukan desain pembelajaran yang tepat sesuai dengan kebutuhan siswa. Jika itu dapat dilakukan, E-Learning menjadi media pembelajaran yang efektif dan efisien dalam mencapai kompetensi yang diinginkan.

Dengan demikian, dalam mengimplementasikan E-learning pada proses pembelajaran ada beberapa hal yang harus dipertimbangkan, yaitu sebagai berikut (Ningrum \& Rosita, 2019):

1. Keuntungan, sejauhmana sistem pembelajaran berbasis E-learning akan memberikan keuntungan bagi institusi, staf, guru, pengelola, dan terutama keuntungan yang akan diperoleh siswadalam meningkatkan kualitas jika dibandingkan dengan penyelenggarakan pembelajaran tatap muka secara konvensional.

2. Biaya pengembangan infrastruktur serta pengadaan peralatan software.

3. Biaya yang diperlukan untuk pengembangan infrastruktur, mengadakan peralatan serta software perlu dipertimbangkan karena biayanya tidak sedikit.

4. Biaya oprasional dan perawatan berbasis E-learning tidak sedikit.

5. Sumber daya manusia juga harus dipertimbangkan sejauhmana kompetensi dan integritasnya.

6. Siswaatau guru juga harus dipertimbangkan, sejauahmana kesiapannya dalam mengikuti kegiatan pembelajaran dengan menggunakan E-learning.

Menurut (Setiawan et al., 2019) mengidentifikasi beberapa keuntungan pemanfaatan E-learning, yaitu:

1. E-learning mampu membuat pendidikan lebih produktif;

2. E-learning mampu menunjang pembelajaran individual, atau dengan kata lain memungkinkan penerapan individualisasi dalam pembelajaran;

3. E-learning mampu membuat pembelajaran lebih ilmiah (scientific), yaitu memungkinkan guru dan siswamenciptakan rangkaian kerja yang sesuai dengan tujuan pembelajaran, memberi kemudahan kepada peserta didik untuk mengetahui apa yang sebenarnya harus ia pahami;

4. E-learning mampu membuat pembelajaran lebih "power full", yaitu dapat menimbulkan suatu obyek tak terwujud ke dalam realita atau mendekati realita, memberi kemantapan dan percepatan pemahaman warga belajar, menata waktu secara efektif dan efisien, mereduksi dan atau menyederhanakan suatu peristiwa tertentu; 
5. E-learning mampu membuat pembelajaran lebih "immediate", yang mana dilukiskan sebagai jembatan antara dunia luar (word outside) dengan dunia dalam (word inside); dan

6. E-learning mampu mempercepat pendidikan lebih "equal"

Sedangkan menurut (Praherdhiono et al., 2019) bahwa E-learning dalam pembelajaran memiliki beberapa manfaat, yaitu: meningkatkan produktivitas pendidikan, memberikan kemungkinan pembelajaran bersifat individual, memberi dasar yang lebih dinamis terhadap pendidikan, pembelajaran lebih mantap, memungkinkan belajar secara seketika dan penyajian pendidikan lebih luas. Sehingga siswadalam dalam mengikuti pembelajaran tidak cepat bosan dan dalam dirinya muncul dorongan atau minat untuk mengikuti kegiatan pembelajaran secara sungguh-sungguh.

\section{Kesimpulan}

Implementasi E-learning sebagai media pembelajaran pada era milenial dapat dilakukan dengan beberapa tahap. yaitu perencanaan, implemtasi, dan evaluasi. Penggunaan E-learning sebagai media pembelajaran pada era milenial sangat mungkin dilakukan. Hal ini bertujuan untuk membangun dan mempertahankan minat belajar siswa. Apabila minat belajar sudab besar maka untuk mencapai tujuan pembelajaran atau kompetensi yang diinginkan akan mudah.

\section{Referensi}

Andayani, S., \& Larasati, N. A. (2019). Implementasi E-Learning Berbasis Learning Management System Pada Program Studi Sistem Informasi Ukmc. Jurnal Sistem \& Teknologi Informasi Komunikasi, 2(2), 31-38.

Bariyah, S. H. (2019). Implementasi E-Learning Dengan Model Flipped Classroom Dalam Aktivitas Belajar Siswa Pada Mata Pelajaran Sistem Komputer. Jurnal Petik, 5(2), 1-8.

Basri, H. (2014). Peningkatan Kualitas Pembelajaran Melalui Adopsi Dan Implementasi Teknologi Instruksional. Jurnal Mudarrisuna: Media Kajian Pendidikan Agama Islam, 4(2), 228-248.

Danim, S. (2008). Media Komunikasi Pendidikan: Pelayanan Profesional Pembelajaran Dan Mutu Hasil Belajar (Proses Belajar Mengajar Di Perguruan Tinggi). Bumi Aksara.

Handoko, F. (2019). Analisis Kesiapan Sekolah Dalam Menghadapi Pembelajaran Di Era Millenial Di Smk Panca Budi 2 Medan Ta 2019/2020.

Hutagalung, J., Winata, H., \& Jaya, H. (2019). Perancangan Dan Implementasi E-Learning Berbasis Web Pada Sma Negeri 1 Siantar. J-Sisko Tech (Jurnal Teknologi Sistem Informasi Dan Sistem Komputer Tgd), 2(1), 62-68.

Maghfiroh, Z. A. (2019). Pemanfaatan Media Internet Sebagai Sumber Pembelajaran Pendidikan Agama Islam Di Era Millenial (Studi Kasus Di Smp Alternatif Qaryah Thayyibah Salatiga Tahun Ajaran 2018/2019). Universitas Islam Sultan Agung.

Miarso, Y. (2009). Menyemai Benih Teknologi Pendidikan (Ed. 1) Cet. Ke-4. Jakarta: Kencana.

Ningrum, M. V. R., \& Rosita, D. (2019). Pengembangan E-Learning Berbasis Moodle Di Fakultas Keguruan Dan Ilmu Pendidikan Universitas Mulawarman. Sebatik, 23(2), 517-521.

Praherdhiono, H., Setyosari, P., Degeng, I. N. S., Slamet, T. I., Surahman, E., Adi, E. P., ... Abidin, Z. (2019). Teori Dan Implementasi Teknologi Pendidikan: Era Belajar Abad 21 Dan Revolusi Industri 4.0. Seribu Bintang.

Putri, D. P. E. (2019). Penggunaan Media Pembelajaran Berbasis Android Untuk Meningkatkan Hasil Belajar Kognitif Siswa. Edugama: Jurnal Kependidikan Dan Sosial Keagamaan, 5(2), 104-111.

Putri, D. P. E., \& Muhtadi, A. (2018). Pengembangan Multimedia Pembelajaran Interaktif Kimia Berbasis Android Menggunakan Prinsip Mayer Pada Materi Laju Reaksi. Jurnal Inovasi Teknologi Pendidikan, 5(1), 38-47.

Sastrawijaya, A. T. (1991). Pengembangan Program Pengajaran. Rineka Cipta.

Setiawan, A., Nurlaela, L., \& Yundra, E. (2019). Pengembangan E Learning Sebagai Media Pembelajaran 
Pendidikan Vokasi. Prosiding Seminar Nasional Santika Ke-1 2019, 52-56.

Simanihuruk, L., Simarmata, J., Sudirman, A., Hasibuan, M. S., Safitri, M., Sulaiman, O. K., ... Sahir, S. H. (2019). E-Learning: Implementasi, Strategi Dan Inovasinya. Yayasan Kita Menulis.

Singer, K. (1987). Membina Hasrat Belajar Di Sekolah, Terj. Bregmen Sitorus, Bandung: Remaja Rosda Karya.

Soejanto, A. (1995). Bimbingan Ke Arah Belajar Yang Sukses. Jakarta: Rineka Cipta.

Susilo, P. H., \& Rohman, M. G. (2019). Efektivitas Sistem Pembelajaran Online Sebagai Media Pembelajaran Berbasis Aplikasi Web Di Era Milenial. Seminar Nasional Sistem Informasi (Senasif), 3(1), 2038-2044.

Wardani, N. I., Sishadiyati, S., \& Fitriyah, Z. (2019). Implementasi E-Learning Sebagai Pendukung Proses Belajar Mengajar Bagi Dosen Dan Mahasiswa Di Upn "Veteran" Jawa Timur. Dinamika Administrasi: Jurnal Ilmu Administrasi Dan Manajemen, 2(1), 1-11.

Yeni, F., \& Fitri, S. M. (2019). Pengenalan Teknologi Dalam Proses Pembelajaran Generasi Millenial Pkbm Bunga Bangsa Di Kampung Cilele Karawang Jawa Barat. Prosiding Abdimasmu, 1(1), 115-121. 